\title{
Initiating the Validation of CCIM Processability for Multi-phase Ceramic (SYNROC) HLW Forms: Plan for Test BFY14CCIM-C
}

FCRD-SWF-2014-000444

Vince Maio

August 2014

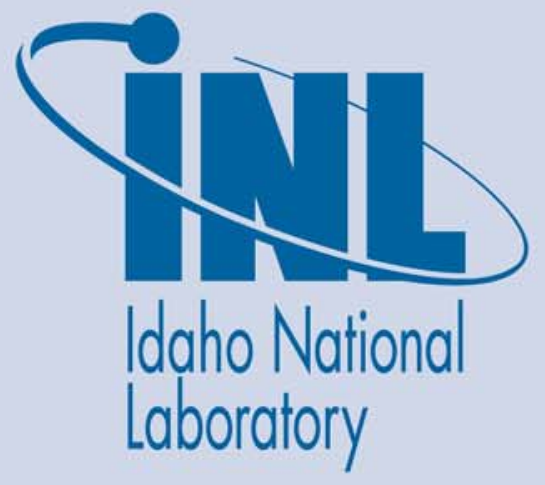

The INL is a U.S. Department of Energy National Laboratory operated by Battelle Energy Alliance 


\title{
Initiating the Validation of CCIM Processability for Multi-phase Ceramic (SYNROC) HLW Forms: Plan for Test BFY14CCIM-C FCRD-SWF-2014-000444
}

\author{
Vince Maio
}

August 2014

\begin{abstract}
Idaho National Laboratory
Idaho Falls, Idaho 83415
\end{abstract}

http://www.inl.gov

Prepared for the

U.S. Department of Energy

Office of Nuclear Energy

Under DOE Idaho Operations Office

Contract DE-AC07-05ID14517 


\section{DISCLAIMER}

This information was prepared as an account of work sponsored by an agency of the U.S. Government. Neither the U.S. Government nor any agency thereof, nor any of their employees, makes any warranty, expressed or implied, or assumes any legal liability or responsibility for the accuracy, completeness, or usefulness, of any information, apparatus, product, or process disclosed, or represents that its use would not infringe privately owned rights. References herein to any specific commercial product, process, or service by trade name, trade mark, manufacturer, or otherwise, does not necessarily constitute or imply its endorsement, recommendation, or favoring by the U.S. Government or any agency thereof. The views and opinions of authors expressed herein do not necessarily state or reflect those of the U.S. Government or any agency thereof. 


\begin{abstract}
This plan covers test BFY14CCIM-C which will be a first-of-its-kind demonstration for the complete non-radioactive surrogate production of multiphase ceramic (SYNROC) High Level Waste (HLW) forms using Cold Crucible Induction Melting (CCIM) Technology. The proof of principle test will occur in Idaho National Laboratory's (INL) CCIM Pilot Plant and is tentatively scheduled for the week of September 15, 2014. The purpose of the test is to begin collecting qualitative data for validating the ceramic HLW form processability advantages of using CCIM technology- as opposed to existing ceramic-lined Joule Heated Melters (JHM) currently producing accepted, but less durable, borosilicate glass (BSG) forms. The objectives of BFY14CCIM-C are to complete crystalline melt initiation with a new joule heated resistive starter ring, sustain inductive melting at temperatures between 1500 to $1700^{\circ} \mathrm{C}$ for two different relatively highly conductive materials representative of the SYNROC formation inclusive of a HLW surrogate, complete melter tapping and pouring of molten ceramic material in to a preheated 4 inch graphite canister and a similar canister at room temperature. Other goals include assessing the performance of a new crucible specially designed to accommodate the tapping and pouring of pure crystalline forms in contrast to less recalcitrant amorphous glass, assessing the overall operational effectiveness of melt initiation using a resistive starter ring with a dedicated power source, and observing the tapped molten flow and subsequent relatively quick crystallization behavior in pans with areas identical to standard HLW disposal canisters. Surrogate waste compositions with ceramic SYNROC forming additives and their measured properties for inductive melting, testing parameters, pre-test modifications, key testing steps, data collection requirements, and sampling/post-demonstration analysis requirements for the produced forms are provided and defined.
\end{abstract}




\section{TABLE OF CONTENTS}

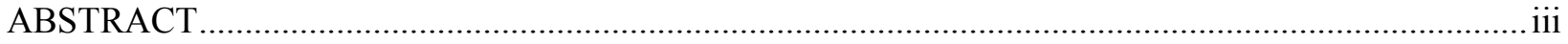

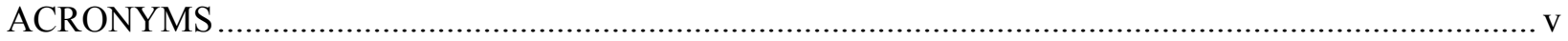

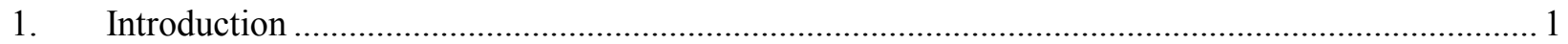

2. Background on SYNROC …………………………................................................... 1

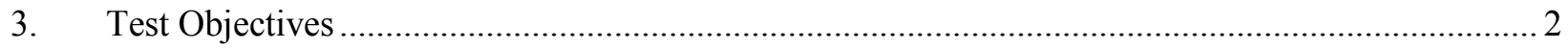

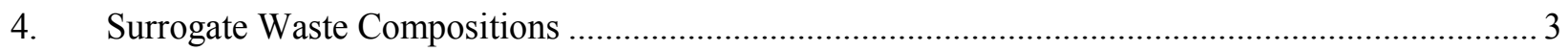

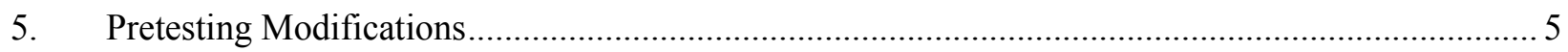

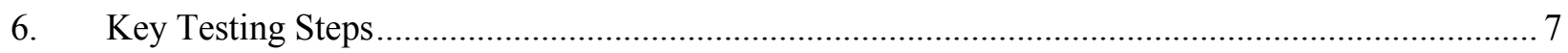

7. Summary of Test Parameters............................................................................................. 8

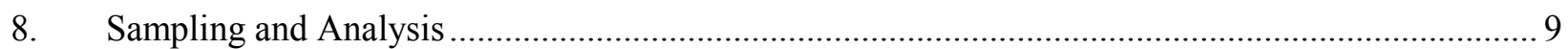

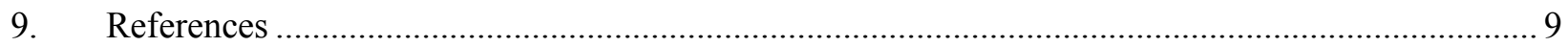

FIGURES

Figure 1 Schematic cut away view of the CCIM. Compared to a JHM, the lack of in-melt electrodes and refractory in a CCIM allow for greater mixing, longer life, greater throughput, less footprint and temperatures exceeding $1700^{\circ} \mathrm{C}$. These higher temperature allow for the potential melt production of more durable HLW forms containing ceramic phases.

Figure 2 The controlled cooling system in its rolling cart in place beneath the crucible and Faraday cage; graphite molds are contained in the three heating mantles.

Figure 3 Full side view of the new CCIM Pilot Plant's Crucible with the remote arm drain plugging and cooling device.

\section{TABLES}

Table 1 Target Oxide Concentrations (wt. \%) in HLW/Ceramic Waste Form........................................... 8

Table 2 Raw Material Recipe Batch Sheets for $50 \mathrm{~kg}$ of Pre-melted HLW/Ceramic Surrogate...............5

Table 3 Target Operating Parameters for Test BFY14CCIM-C .......................................................... 8 


\section{ACRONYMS}

BSG Borosilicate Glass

CCIM Cold Crucible Induction Melter

CS Alkali and Alkaline Earth Fission Products (Cesium and Strontium)

DOE-NE Department of Energy Office of Nuclear Energy

FCRD Fuel Cycle Research and Development

FPs Fission Products

HLW High Level (Liquid) Waste (Liquid Raffinate from SNF recycling)

INL Idaho National Laboratory

JHM Joule Heated Melter

LC Inductance-Capacitance Circuit

LN Lanthanide Fission Products

PNNL Pacific Northwest National Laboratory

RF Radio Frequency

SEM Scanning Electron Microscopy

SNF Spent Nuclear Fuel

SRNL Savannah River National Laboratory

SYNROC Synthetic Rock developed exclusively as a HLW form

TC Thermocouple

TM Transition Metal Fission Products

XRD X-ray Diffraction 


\section{Initiating the Validation of CCIM Processability for Multi-phase Ceramic (SYNROC) HLW Forms: Plan for Test BFY14CCIM-C}

\section{Introduction}

Compared to High Level Waste (HLW) glass disposal forms and, in particular, the widely deployed borosilicate glass (BSG) forms; multi-phase pure ceramic forms offer significant advantages in terms of higher HLW loadings, longer radionuclide retention, increased radiation and radiation heat tolerance and increased durability. Additionally, Cold Crucible Induction Melting (CCIM) technology, in contrast to established Joule Heated Melters (JHM), better accommodates the formation of ceramic forms given the CCIM's higher temperatures, efficient mixing, tolerance to crystal formation and bottom drain configuration. See Figure 1. Consequently, this CCIM/ceramic waste form combination may be the optimum option for the future HLW produced from advanced commercial fuel cycle technologies presently under development by the Department of Energy's (DOE's) Fuel Cycle Research and Development Program (FCRD).

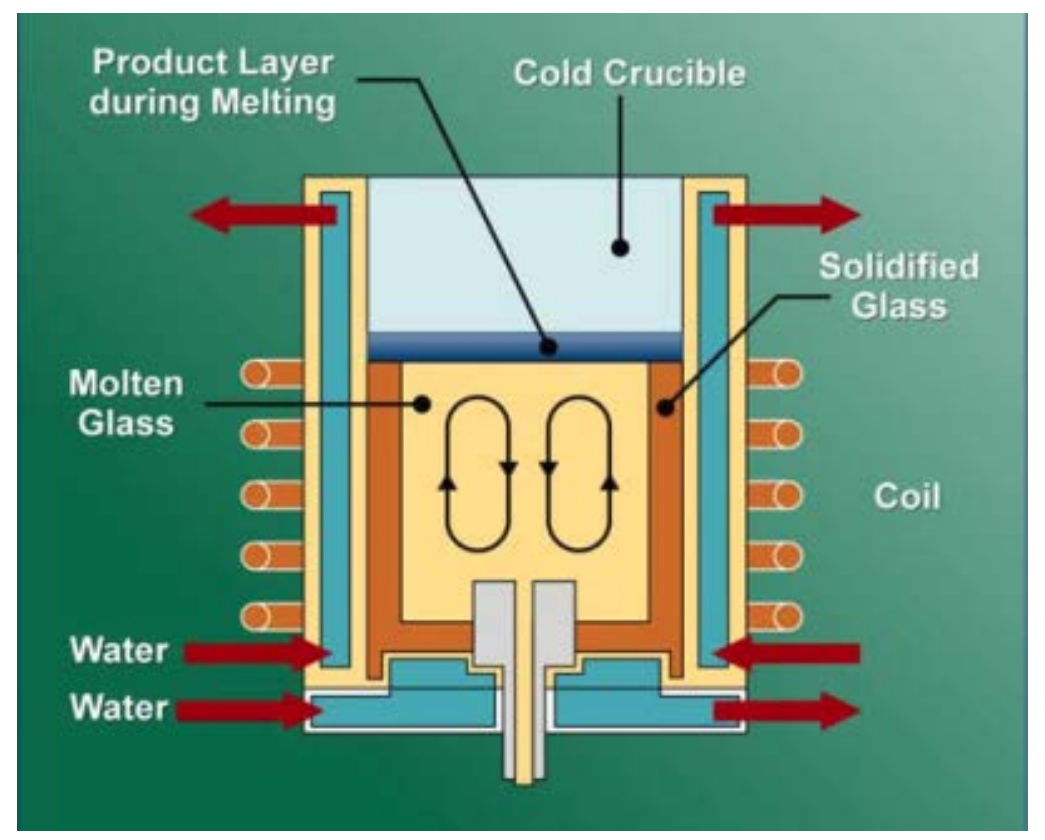

Figure 1 Schematic cut away view of the CCIM. Compared to a JHM, the lack of in-melt electrodes and refractory allow for greater mixing, longer life, greater throughput, less footprint and temperatures exceeding $1700^{\circ} \mathrm{C}$. Higher

temperature allows for the potential melt production of highly durable HLW forms containing ceramic phases.

To begin validating the above premise, a first-of-a-kind test to demonstrate the complete processability of Cold Crucible Induction Melters (CCIMs) toward producing advanced High Level Radioactive (HLW) Waste forms consisting of multiple crystalline phases is scheduled for the week of September 15, 2014. The proof of principle test will deploy Idaho National Laboratory's integrated CCIM Pilot Plant located in West Bay 1 of the Idaho Engineering Development Facility (IEDF) and has been designated BFY14CCIM-C. After a brief background section addressing the multi -phase ceramic SYNROC HLW form, this test plan outlines the objectives, two different HLW surrogate/ceramic SYNROC compositions to be tested, key pretest modifications, key testing steps, test parameters, data collection requirements and post-test waste form sampling and analysis.

\section{Background on SYNROC}

To ensure that HLW from future aqueous-based commercial Spent Nuclear Fuel ( SNF) recycling is in an advanced enough form to satisfy long standing environmental legacy issues prior to geological 
disposal, as well as open up options for safer disposal, necessitates investigating the use of ceramic crystalline materials in contrast to the accepted glass-based mediums. Ceramic containing HLW forms will achieve the long term durability, high inherent radioactive heat tolerance and lasting insolubility current amorphous borosilicate glass (BSG) waste forms cannot provide. One such multi-phase ceramic HLW form with a considerable research, development and demonstration history is SYNROC[ref2]. Proposed and developed by Ringwood and colleagues, starting in 1978, SYNROC is a multi-phase ceramic waste form that contains synthetic minerals whose natural geological analogs have contained natural radioactive elements for millions of years. Consisting of the three titanate ceramic phases of hollandite, zirconalite, and pervoskite, SYNROC is superior and unique as a HLW form since it is not only highly insoluble: but each separate phase- due to their range of cation valances- creates a dilute solid solution of all the radioactive elements in HLW. These include the remaining trace actinides not removed from recycling plus all the fission, daughter and activation products.

The majority of technologies demonstrated for producing SYNROC HLW forms (i.e. involving mostly non-radioactive HLW surrogates) over the past 40 years have been dry based pressing and sintering methods. These methods involve calcination of the liquid HLW from SNF recycling into a dry particulate and then sintering the form; after the addition of SYNROC additives or precursors, which may include sol-gel methods. Various methods for final sintering and durable form production include conventional bricking, hot uniaxial pressing (HUPing) and hot iso-static pressing (HIPing). However, dry methods produce undesired radiological control problems for cell or canyon operations as a result of the dust produced. Additionally these methods contain undesirable additional steps, such as calcination prior to sintering. However, since SYNROC exhibits congruent melting at high temperatures (e.g., 1500 to $1700^{\circ} \mathrm{C}$ ), formation of the form via melt routes are possible. Currently, these routes are favored over dry techniques based in part on the successful experience with JHMs and their 40 plus history associated with the production of glass HLW forms. However, since the currently used conventional JHMs are not adequate at temperatures above $1200^{\circ} \mathrm{C}$ due to corrosion concerns surrounding their in-melt electrodes and refractory, CCIM technology must be tested as a SYNROC HLW form method to begin validating their inherent higher temperature capabilities.

\section{Test Objectives}

The overall objective of BFY14CCIM-C will be to convert- upon melting, melter tapping, and subsequent pouring and crystallization- the dry particulate surrogate HLW/ ceramic- forming additive mix in the CCIM into durable multi-phase ceramic HLW forms with relatively high waste loadings. Specific objectives include:

The successful melt initiation (up to $1700^{\circ} \mathrm{C}$ ) of a torus around the tungsten initiation ring of both of the two different (see section 4) dry particulate HLW surrogate/ ceramic additive mixes (i.e., that have been pre-charged to the crucible). As a result of the pure oxide ceramic nature of these surrogates, initiation is expected to be challenging compared to surrogates forms that are all amorphous or part amorphous. As such, initiation will be attempted using aggressive methods to ensure high initiation ring temperatures are maintained for up to at least two hours until heat transfer of sufficient duration is maintained long enough to overcome the latent heat barrier for solid to liquid phase change. This latter condition is not present for melting amorphous (glassy) material. As a result, a new method of melt initiation will be attempted involving a resistive power starter ring. The new system will deploy a dedicated power source that will continually supply energy to a starter ring made of tungsten (melting temperature equal to greater than $2800^{\circ} \mathrm{C}$ ) or an alternative such as platinum /rhodium as opposed to inducing a current in a titanium ring as before. Power will be cut from the ring once the melt is initiated and the RF generator will then be subsequently tuned to inductively grow and sustain the entire melt.

As implied by the last paragraph, successful coupling of the melts via induction after initiation is another objective of test BFY14CCIM-C. As determined by earlier and smaller-scale SYNROC pretests 
completed by PNNL for SRNL [ref.2], the high conductivity (i.e., 130S/m) of the multi-phase ceramic SYNROC forms indicates that RF generator coupling will be less arduous then the glass ceramics of the last two years. However, successful coupling, as detailed later in this test plan, will depend on properly "re-strapping" the RF generator for the lower frequencies needed to match the high conductivity as well as designing, fabricating and installing a new coil around the new crucible to increase inductance.

The successful tap and pour of a molten surrogate/multi-phase ceramic HLW form from the CCIM. As in previous tests, both pours are to occur in to 4" diameter graphite molds (equipped with axial thermocouple trees) surrounded by heating mantles on a custom designed rolling cart below the crucible as shown in Figure 2. For each of the two different surrogates, one pour is to occur in a graphite canister that is not pre-heated and then cooled naturally under ambient conditions. The second tap is to be poured into another graphite 4 " diameter mold pre -heated to $\sim 1000^{\circ} \mathrm{C}$. The heat to this mantle is to be turned off once the pour is complete. The justification for the two different initial temperature pours is to determine changes in crystal size and ceramic type proportions as a function of temperature; which will be determined by post analysis.

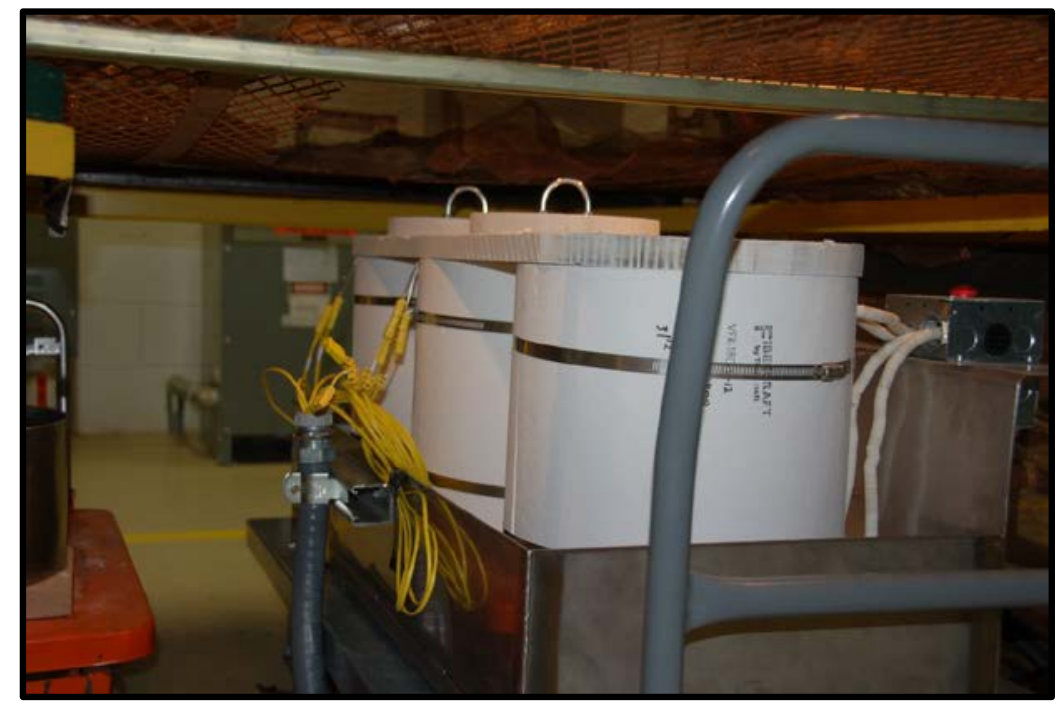

Figure 2 The controlled cooling system in its rolling cart in place beneath the crucible and Faraday cage; graphite molds are contained in the three heating mantles.

Observe the behavior of the molten ceramic forms when they are poured into a pan with a standard disposal canister diameter. This test is important to visually observe if the molten waste can completely fill or partially fill the total cross section of a standard canister diameter. There is value in assessing the cooling rate of the SYNROC/HLW ceramic as it flows to the outer edges of the canister to ensure there are no voids in filling due to quick crystallization. The first ceramic/HLW surrogate pour will take place in the 2 foot diameter stainless steel pan to represent flow into a US standard disposal canister. The second long pour utilizing the other surrogate is planned to occur in the 1.4 foot stainless steel pan to represent flow into an international standard disposal canister..

\section{Surrogate Waste Compositions}

The non-radioactive dry oxide HLW surrogates for the two multi-phase ceramic SYNROC tests is being prepared by MOSCI Corporation (Rolla, MO) based on recipes provided through smaller scale testing at SRNL and contains representatives of the fission products expected in HLW from future SNF recycling. In general it is the combination of projected raffinate streams produced separately during an 
advanced SNF aqueous separation process. The surrogate contains representatives of the alkaline and alkaline earth fission products; mainly cesium and strontium, the lanthanide fission products and the transition metal fission products. The surrogate also contains the correct amount of oxide frits (e.g., titanium oxide) required to produce the desired ceramic SYNROC formations as determined by SRNL. The two surrogates have been designated Fe-MP and CAF-5\%TM-MP and their expected waste form composition in oxides is provided in Table 1 below. The following Table 2 provides the recipes for making the two surrogates for charging to the CCIM Pilot-Plant prior to melting. The difference between the two surrogates is significant and has purpose with respect between ensuring the validation of CCIM technology for multi-phase ceramic processability and ensuring the production of an acceptable SYNROC (i.e., proper microstructure) surrogate waste form product. Their differences rest with their compositions and the amount of high temperature ceramic additives included with each surrogate. As such, the Fe-MP surrogate (representing "iron -melt product ") contains iron oxide, but does not contain the required SYNROC/ HLW surrogate additives of chromium oxide and alumina. As a result it will melt at a lower temperature, likely drain repeatedly without solidification, but result in an imperfect SYNROC waste form (e.g., lacking the zirconalite phase). In contrast, the CAF-5\%TM-MP surrogate (representing a "chromium oxide, alumina, iron, $5 \%$ transition metal fission product melt product") is expected to produce all the appropriate three titanium ceramic phases of SYNROC, yet its high melting point of over $1650^{\circ} \mathrm{C}$ challenges CCIM Pilot Plant operation in terms of tapping and pouring. Consequently for demonstration BFY-14CCIM-C, the Fe-MP surrogate will be tested first, and if successful, followed by the more challenging test with the CAF-5\%TM-MP surrogate.

Table 1 Target Oxide Concentrations (wt. \%) in HLW/Ceramic Waste Form

\begin{tabular}{|c|c|c|}
\hline Component & Fe-MP & CAF-5\%TM-MP \\
\hline $\mathrm{Al}_{2} \mathrm{O}_{3}$ & 0.00 & 1.25 \\
\hline $\mathrm{CaO}$ & 1.37 & 1.75 \\
\hline $\mathrm{CdO}$ & 0.11 & 0.11 \\
\hline $\mathrm{Cr}_{2} \mathrm{O}_{3}$ & 0.00 & 6.23 \\
\hline $\mathrm{Eu}_{2} \mathrm{O}_{3}$ & 0.17 & 0.17 \\
\hline $\mathrm{Fe}_{2} \mathrm{O}_{3}$ & 15.13 & 6.55 \\
\hline $\mathrm{Gd}_{2} \mathrm{O}$ & 0.16 & 0.16 \\
\hline $\mathrm{SrO}$ & 0.97 & 0.96 \\
\hline $\mathrm{TiO}_{2}$ & 48.65 & 49.48 \\
\hline $\mathrm{ZrO}_{2}$ & 2.96 & 3.06 \\
\hline $\mathrm{BaO}$ & 12.63 & 12.57 \\
\hline $\mathrm{Ce}_{2} \mathrm{O}_{3}$ & 3.07 & 3.03 \\
\hline $\mathrm{Cs}_{2} \mathrm{O}$ & 2.85 & 2.81 \\
\hline $\mathrm{La}_{2} \mathrm{O}_{3}$ & 1.57 & 1.55 \\
\hline $\mathrm{MoO}_{3}$ & 0.84 & 0.83 \\
\hline $\mathrm{Nd}_{2} \mathrm{O}_{3}$ & 5.18 & 5.11 \\
\hline $\mathrm{Pr}_{2} \mathrm{O}_{3}$ & 1.43 & 1.41 \\
\hline $\mathrm{SeO}_{2}$ & 0.08 & 0.08 \\
\hline $\mathrm{SnO}_{2}$ & 0.07 & 0.07 \\
\hline $\mathrm{Sm}_{2} \mathrm{O}_{3}$ & 1.07 & 1.05 \\
\hline $\mathrm{TeO}_{2}$ & 0.65 & 0.67 \\
\hline $\mathrm{Y}_{2} \mathrm{O}_{3}$ & 0.62 & 0.64 \\
\hline $\mathrm{Rb}_{2} \mathrm{O}$ & 0.42 & 0.43 \\
\hline
\end{tabular}


Table 2 Raw Material Recipe Batch Sheets for $50 \mathrm{~kg}$ of Pre-melted HLW/Ceramic Surrogate

\begin{tabular}{|c|c|c|c|}
\hline \multirow{2}{*}{ Component } & \multirow{2}{*}{ Source } & \multicolumn{2}{|c|}{ Amount Needed (g) } \\
\cline { 3 - 4 } & & Fe-MP & CAF-5\%TM-MP \\
\hline $\mathrm{Al}_{2} \mathrm{O}_{3}$ & $\mathrm{Al}_{2} \mathrm{O}_{3}$ & 0.000 & 627.122 \\
\hline $\mathrm{CaO}^{\dagger}$ & $\mathrm{CaCO}_{3}$ & 1224.233 & 1561.037 \\
\hline $\mathrm{CdO}$ & $\mathrm{CdO}$ & 54.405 & 56.35 \\
\hline $\mathrm{Cr}_{2} \mathrm{O}_{3}$ & $\mathrm{Cr}_{2} \mathrm{O}_{3}$ & 0.000 & 3116.102 \\
\hline $\mathrm{Eu}_{2} \mathrm{O}_{3}$ & $\mathrm{Eu}_{2} \mathrm{O}_{3}$ & 85.096 & 83.95 \\
\hline $\mathrm{Fe}_{2} \mathrm{O}_{3}$ & $\mathrm{Fe}_{2} \mathrm{O}_{3}$ & 7564.137 & 3273.922 \\
\hline $\mathrm{Gd}_{2} \mathrm{O}$ & $\mathrm{Gd}_{2} \mathrm{O}$ & 79.516 & 78.44 \\
\hline $\mathrm{SrO}^{\dagger}$ & $\mathrm{SrCO}_{3}$ & 693.638 & 684.311 \\
\hline $\mathrm{TiO}_{2}$ & $\mathrm{TiO}_{2}$ & 24326.010 & 24741.113 \\
\hline $\mathrm{ZrO}_{2}$ & $\mathrm{ZrO}_{2}$ & 1478.710 & 1531.767 \\
\hline $\mathrm{BaO}^{\dagger}$ & $\mathrm{BaCO}_{3}$ & 8128.208 & 8091.548 \\
\hline $\mathrm{Ce}_{2} \mathrm{O}_{3}$ & $\mathrm{Ce}_{2} \mathrm{O}_{3}$ & 1610.772 & 1589.112 \\
\hline $\mathrm{Cs}_{2} \mathrm{O}^{\dagger}$ & $\mathrm{Cs}_{2} \mathrm{CO}_{3}$ & 1648.347 & 1626.182 \\
\hline $\mathrm{La}_{2} \mathrm{O}_{3}$ & $\mathrm{La}_{2} \mathrm{O}_{3}$ & 783.995 & 773.453 \\
\hline $\mathrm{MoO}_{3}$ & $\mathrm{MoO}_{3}$ & 418.503 & 412.875 \\
\hline $\mathrm{Nd}_{2} \mathrm{O}_{3}$ & $\mathrm{Nd}_{2} \mathrm{O}_{3}$ & 2589.138 & 2554.321 \\
\hline $\mathrm{Pr}_{2} \mathrm{O}_{3}^{\dagger}$ & $\mathrm{Pr}_{6} \mathrm{O}_{11}$ & 740.224 & 730.270 \\
\hline $\mathrm{SeO}_{2}$ & $\mathrm{SeO}_{2}$ & 40.455 & 41.90 \\
\hline $\mathrm{SnO}_{2}$ & $\mathrm{SnO}_{2}$ & 34.875 & 36.12 \\
\hline $\mathrm{Sm}_{2} \mathrm{O}_{3}$ & $\mathrm{Sm}_{2} \mathrm{O}_{3}$ & 532.894 & 525.728 \\
\hline $\mathrm{TeO}_{2}$ & $\mathrm{TeO}_{2}$ & 325.037 & 336.700 \\
\hline $\mathrm{Y}_{2} \mathrm{O}_{3}$ & $\mathrm{Y}_{2} \mathrm{O}_{3}$ & 311.087 & 322.249 \\
\hline $\mathrm{Rb}_{2} \mathrm{O}^{\dagger}$ & $\mathrm{Rb}_{2} \mathrm{CO}_{3}$ & 258.515 & 267.790 \\
\hline & & & \\
\hline
\end{tabular}

${ }^{\dagger}$ Source component was in the form of carbonate., ${ }^{\ddagger}$ Source component was in the form of a different oxide.

\section{Pre-testing Modifications}

Test BFY14 CCIM-C will require three significant modifications prior to the actual SYNROC demonstration. As described below in order, these modifications include RF generator and main (inductance-capacitance) LC circuit changes, complete fabrication and testing of a new melter and associated systems to enhance melter tapping/ pouring, and installation/testing of a joule -heated resistive melt initiation ring.

The Cold Crucible Induction Melting Pilot Plant and its associated RF generator was designed to melt HLW surrogates -in glass only waste forms -with a mean electrical conductivity of $20 \mathrm{~S} / \mathrm{m}$. In addition modifications allowing operation with compromised efficiency over conductivities as low as 10 $\mathrm{S} / \mathrm{m}$ for glass ceramics have been made. It is possible to operate at high efficiency at higher conductivities, as is required due to the unique presence of titanium in the proposed SYNROC HLW surrogates. However, this will require RF generator and melter coil modifications. These higher frequencies may also be subject to constraints not present for melting lower conductivity glass and glass ceramics. However, these modifications can be completed with little investment in time or effort as necessary for test run BFY15CCIM-C

Based on small scale tests completed by PPNL as directed by SNRL[ref. 2] one of the representative SYNROC ceramic HLW surrogates (i.e. the Fe -MP surrogate) exhibited a melt conductivity of $\sim 100$ 
$\mathrm{S} / \mathrm{m}$, and since frequency is inversely proportional to melt conductivity, an optimal operating induction frequency of $395 \mathrm{kHz}$. A move to the lower frequency will require two system modifications prior to test BFY14CCIM-C: 1) the fabrication of a new primary inductor (e.g., the coil around the CCIM) and 2) the addition of an impedance matching network to the existing radio frequency (RF) generator. The fabrication of a new inductor will require determining the number of turns to attain the desired inductive reactance and specification of coil spacing compatible with electrical arcing issues. Fortunately the INLCCIM Pilot Plant's RF frequency generator is designed for lower frequency operation and the impedance matching network is already installed in the existing RF generator system. To date these components, over the last eight years of CCIM Pilot Pant operation, have been confined to frequencies in the range of $1.8 \mathrm{MHz}$ and above. The RF Generator's documentation provides detailed instructions for the "re-strapping" of the network to accommodate operation at $395 \mathrm{KHz}$. In fact, after re-strapping, the generator is designed to operate over the range of $200 \mathrm{kHz}$ to $400 \mathrm{kHz}$. Recent melt conductivity data as high as $130 \mathrm{~S} / \mathrm{m}$ as supplied through small scale testing at PNNL gave values of $130 \mathrm{~S} / \mathrm{m}$ indicating operation at $304 \mathrm{KHz}$ which is well within the specified operating range. Regulatory considerations on free-field radio frequency emissions constrain the operating frequency range. Based on current federal regulations this would prohibit generator operation in or near the AM broadcast band, which works out to a melt electrical conductivity "prohibited" range of $26 \mathrm{~S} / \mathrm{m}$ to $99 \mathrm{~S} / \mathrm{m}$. However, this is not a hard constraint due to the existence of a Faraday cage shield that is effective at the upper end of the broadcast band.

Besides being fabricated with features to enhance its reliability, operability and maintainability (ROM) compared to over ten years of operation with the existing melter, the new melter will be equipped with a unique tapping /melt pouring/melt draining design. The two key features of that design includes a replaceable conical sleeve for a drain hole that will be flush with both the top and bottom end of the melter's copper base. The conical sleeve (which can be graphite or platinum) will be surrounded by boron nitrate insulation to enough ensure heating of the sleeve while maintaining cooling of the base. The other feature as indicated in figure 3 is an air remotely operated arm with a cooling plate attached to its end. The purpose of the arm and plate will be to ensure cooling of the drain hole during periods of no tapping.

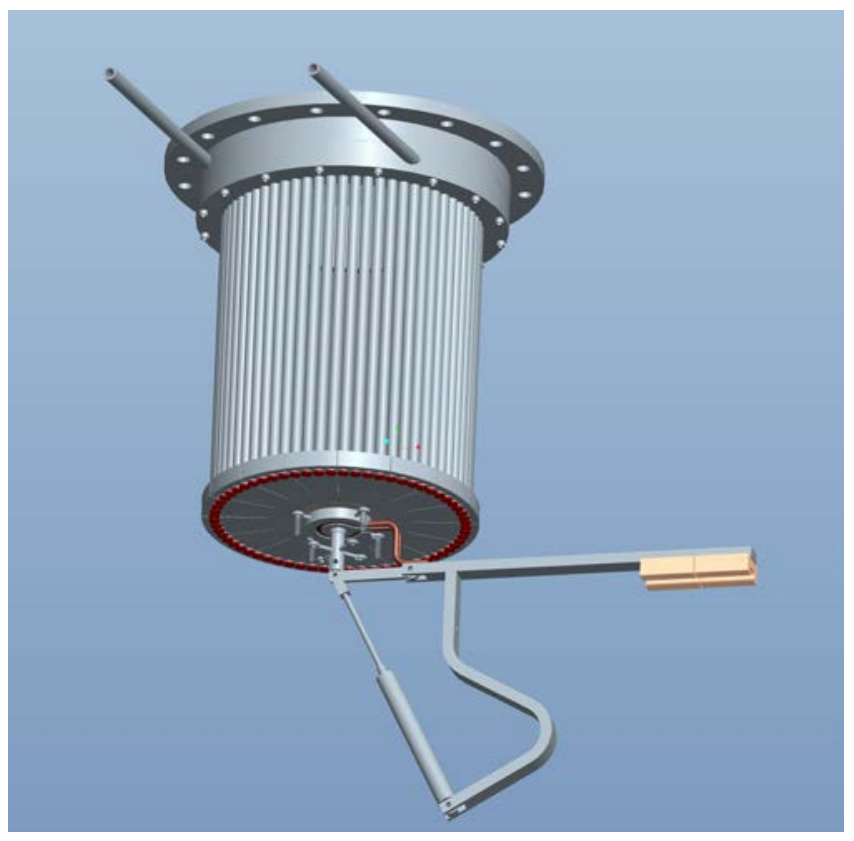

Figure 3 Full side view of the new CCIM Pilot Plant's Crucible with the remote arm drain plugging and cooling device 
Test run BFY14CCIM-C will also be utilized to experiment with a new surrogate initiation technique. Since a pure ceramic solid particulate mix of oxides and other ceramics is mandatory for producing the SYNROC, no amorphous material is originally in the charge. This will require more initiation power putting the present induction ring arrangement at greater risk of failure as evidenced by the previous difficulties and long times required in initiating melts with glass-ceramics over the last two years. To reduce this risk a joule-heated induction ring design with a continuous power source will be utilized. Design calculations indicate that a power supply of near 4000 watts that supplies up to 350 amps to an initiation ring of either tungsten or platinum/rhodium will ensure reaching temperatures at $1700^{\circ} \mathrm{C}$. At this temperature, the calculations indicate a solid ceramic torus of sufficient size will phase change to molten liquid to allow inductive coupling with the RF generator by tuning in to the appropriate frequency of the surrogate at melt temperatures.

\section{Key Testing Steps}

Based on the discussion above, the following steps are listed below to meet the particular BFY14CCIM- test objectives. The Operating Manuals of references 3 and 4 are to be used for all CCIM Pilot Plant operational steps.

1. After pre-coating and drying the crucible as well as installing the compressed new induction coil assembly with turns to provide the lower frequencies, load the newly design and tested crucible (using respirators and the fume trunk) with $25 \mathrm{kgs}$ of the pre-weighed surrogate HLW/ ceramic solid mix (i.e., start with the Fe-MP surrogate as per section 4) and insert, install and connect the new resistive starter ring configuration. Position the induction ring $1 / 4$ in. down the granulated bed's top surface when the entire surrogate is loaded in the crucible. As with the previous glass ceramic tests utilize a vertical initiation wire ring with a high frequency of waves placed at the skin depth of the new melter. As per the Operating Manuals of reference, pre-start the RF generator and cooling systems for both the generator and crucible.

2. Turn on power to the resistive starter ring energy source. When ignition of the melt is observed to a degree that constitutes a glowing torus of the surrogate around the ring with a diameter of at least two inches, eliminate the initiation ring 's power source.

3. Increase the power of the RF generator to the crucible's L-C circuit by bringing power levels up accordingly per the Operating Manual and tune, via the vacuum tubes, the generator's frequency to match and maximize heating of the glowing molten torus.

4. As observable via the view ports and cameras, conductive heat transfer will, within $\sim 40$ minutes, elevate the temperature of the surrogate dry solid waste in the growing annular region. When coupling is successful and generator load is obtained, besides notable changes in both grid and plate current, heat losses as a result of conduction and convection (which are proportional to the crucible's cross-sectional surface area) will be overcome by the growing melt region as the melt incorporates through complete inductive coupling more and more of the un-melted HLW/ ceramic mix.

5. Stabilize all RF generator and cooling system parameters to maintain (for at least a half hour) a molten temperature in the crucible in the range of $1500^{\circ} \mathrm{C}$ to $1700^{\circ} \mathrm{C}$ as measured by the appropriate type D platinum/rhodium thermocouple (TC) readings. The latter temperature is for surrogate Fe-MP and the former is for surrogate CAF-5\%TM-MP Record data as appropriate and document through both written and instrument validation the achievement of a maximum temperature of $1700^{\circ} \mathrm{C}$ or above and the total time that temperature is maintained. The reaching of this temperature for sufficient time will ensure all the crystals are fully molten and help ensure tapping and draining for both surrogates. 
6. To meet the objectives, prepare to begin crucible tapping and draining operations via operation of the remote armed cooling plate.

7. The first tap and pour is to be done in a 4" diameter graphite mold at ambient conditions. This pour is to last long enough to fill at least 6" of the graphite mold's height. Time from start of tap to stopping of the pour is to be recorded to determine mass flow rates at a later time. Pyrometer readings of the pour are to be taken at least twice during the pour and the temperatures recorded. Terminate the pour by increasing the vacuum on the bed with the off -gas exhaust compressor and remotely replace the cooling cap.

8. The second tap is to be done in a 4" diameter graphite mold pre -heated to $\sim 1100^{\circ} \mathrm{C}$. This pour is to last long enough to fill at least 6" of the graphite molds height. Immediately after the pour is complete, the power source to the heat mantle is to be turned off. Time from start of tap to stopping of the pour is to be recorded to determine mass flow rates at a later time. Pyrometer readings of the pour are to be taken at least twice during the pour and the temperatures recorded. Terminate the pour by increasing the vacuum on the bed with the off -gas exhaust compressor and remotely replace the cooling cap.

9. The last pour is to "dump" the remaining molten bed into a 6" high stainless steel pan $2 \mathrm{ft}$. in diameter (US standard canister size) or into a 6" high stainless steel pan $1.4 \mathrm{ft}$. diameter (European standard canister size). The purpose of this pour is to qualitatively determine the flow characteristics of a ceramic waste form in standard canisters. Examples to be noted through observation include if the ceramic cools before filling the entire base area of the canister. The time from start of tap to stopping of the pour in the pan is to be recorded to determine mass flow rates at a later time. Pyrometer readings of the pours are to be taken at least twice during the pour and the temperatures recorded The recommendation is to use the US sized standard canister for the final pour dump involving the Fe-MP surrogate and the European standard diameter canister for surrogate CAF-\%5TM. .

\section{Summary of Test Parameters}

Table 3 Target Operating Parameters for Test BFY14CCIM-C

\begin{tabular}{|c|c|c|}
\hline Parameter & Units & Value/Description \\
\hline \multicolumn{3}{|l|}{ Melter Feed: } \\
\hline $\begin{array}{l}\text { Projected surrogate waste (HLW) } \\
\text { loading on a mass basis in the final } \\
\text { glass-ceramic waste form }\end{array}$ & $\begin{array}{l}\text { mass } \\
\text { percent }\end{array}$ & $\sim 22 \%$ (expected) \\
\hline Melter feed rate & na & $\begin{array}{c}\text { None } \\
\text { Pre-charged HLW surrogate and SYNROC dry oxide } \\
\text { particulate mixes only }\end{array}$ \\
\hline Duration & Hrs. & $\begin{array}{c}30 \text { minutes }-1 \text { hour of sustained melting for both } \\
\text { surrogates }\end{array}$ \\
\hline \multicolumn{3}{|l|}{ Melter: } \\
\hline Induction power & $\mathrm{kW}$ & $\begin{array}{l}\text { Up to } 55 \text { should be sufficient enough for maintaining } \\
\text { the high target temperatures }\end{array}$ \\
\hline Desired induction frequency & $\mathrm{MHz}$ & $310 \mathrm{kHz}-400 \mathrm{kHz}$ \\
\hline $\begin{array}{l}\text { Estimated melt conductivity near } \\
\text { the melt temperature }\end{array}$ & $\begin{array}{c}\mathrm{S} / \mathrm{m} \\
\mathrm{mhos}\end{array}$ & $100-130 \mathrm{~S} / \mathrm{m}$ at surrogate melt temperatures \\
\hline $\begin{array}{l}\text { Melt viscosity range near melt } \\
\text { temperature }\end{array}$ & Pa-sec & $\begin{array}{l}\text { The melt viscosity must be } 20 \text { Poise or less to ensure } \\
\text { successful pouring. This will require tapping/pouring } \\
\text { drain temperatures of at least } 1600^{\circ} \mathrm{C} \text { for the CAF - } \\
5 \% \mathrm{TM} \text { surrogate and } 1450^{\circ} \mathrm{C} \text { for the Fe-MP surrogate }\end{array}$ \\
\hline Desired Melter Temperature Range & ${ }^{\circ} \mathrm{C}$ & $1600-1700^{\circ} \mathrm{C}$ \\
\hline
\end{tabular}




\section{Sampling and Analysis}

Once the two tapped and poured melts for each of the two multi-phase ceramic SYNROC HLW surrogates are cooled to room temperature, each of the four graphite mold cylinders with forms will be shipped to SRNL and /or PNNL for analysis. There they will be cored both vertically and radially to measure the degree of space and temperature homogeneity in terms of specific ceramic phases and their crystal sizes, and then analyzed for the following:

- X-Ray Diffraction (XRD) - for surrogate phase identification only (i.e., different ceramic phases, such as hollandite, pervoskite, and zirconalite, plus the identification of amorphous phases if any)

- Energy Dispersive Spectroscopy (EDS) - for quantitative phase analysis. This analysis provides the amount of each phase and classifies the crystalline phases

- Scanning Electron Microscopy (SEM) micrographs/elemental spot analysis - along with EDS, provides HLW surrogate waste component distributions in the various phases. The expected distribution of the fission product surrogates among the appropriate three phases will provide a significant portion of the validation for successful CCIM melting into a durable SYNROC form

X-ray tomography will also be attempted to 3-diamensionally locate the three various types of ceramic phase (hollandite, zirconalite, pervoskite) in the waste forms after they are removed from the graphite mold canister. Additional samples may also be taken based on the direction of our research partners and submitted for analysis by optical microscopy, SEM, and X-ray powder diffraction.

\section{References}

1. Ringwood, A.E.; Kesson,S.E.; Chapter 4, SYNROC from Radioactive Waste Forms from the Future; Werner Lutze and Rodney C. Ewing, North- Holland Press,, 1988

2. Amoroso J.W.; Marra, J.C.; Ceramic Waste Form Data Package, Savannah River National Laboratory, FCRD-SWF-2014-000581, document SRNL-STI-2014-0027, June 13, 2014.

3. INL/MIS-14-1238, INL Cold Crucible Induction Melter Radio Frequency Generator Operations Manual

4. INL/MIS-14-1239 INL Cold Crucible Induction Melter Balance of Plant Operations Manual 